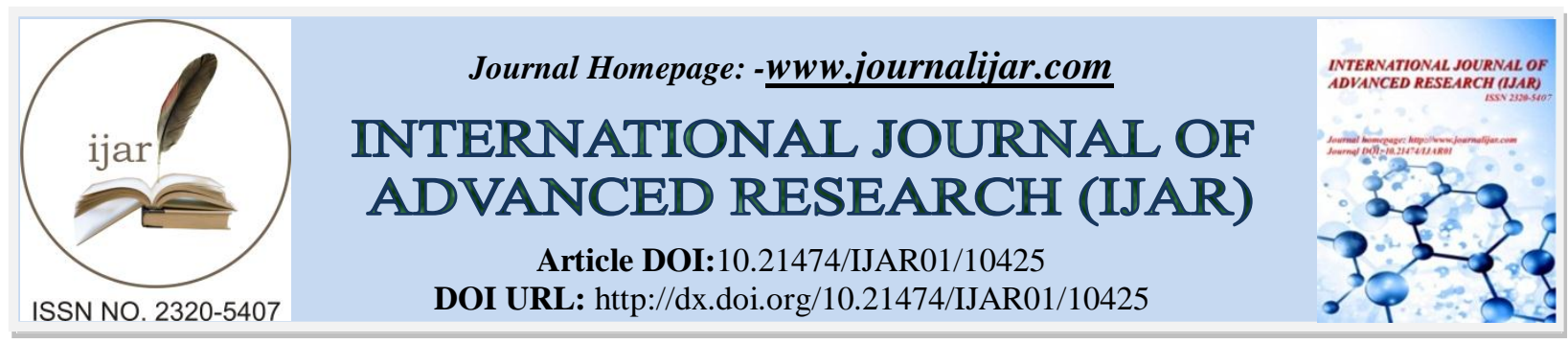

RESEARCH ARTICLE

\title{
PURE INTERNAL SUBTALAR DISLOCATION : ABOUT A CASE
}

\section{AIT Hadj Sliman, A. Abdelaoui, H. ZIM, M.A. Benhima, I. Abkari, Y. Najeb and H. Saidi} Orthopaedic and Trauma Service at the Mohammed VI Marrakech University Hospital.

\section{Manuscript Info}

Manuscript History

Received: 30 November 2019

Final Accepted: 31 December 2019

Published: January 2020

Key words:

Internalsubtalar Dislocation,

Orthopedictherapy, Domesticaccident
Abstract

Pure subtalar dislocation is a rare affection. Herewe report the case of a youngfemalpatient presentinga pure internalsubtalar dislocation as a result of a domesticaccident. Sheunderwentan orthopedic therapy, achieving a good functionaloutcome.

\section{Introduction:-}

Pure subtalar dislocation is the displacement of the calcaneo-pedious set below the slopemaintained in the tibiofibular mortaise, withoutassociated fracture. It is a rare lesion, $1 \%$ of all dislocations observed in traumatology.

\section{Patient and Observation:-}

This was a 38-year-old femalpatient with nonesignificantmedicalhistorywhohadsuffered a rightankleinjuryfollowing a domestic accident (slide on the sidewalk) with a mechanismdescribing a reversal and an equinus of the right foot. The clinicalstudyhadobjectified a pain withfunctional impotence of the limb, a deformity of the middle tarsal regionwithedema of the ankle, abrasions of the outer face of the anklewithout skin opening or notablevasculonervouslesions (Figure 1).Standard radiography made it possible to diagnose a pure subtalar dislocation (Figure2). The reductionwascarried out undergeneralanesthesia by the tear-pulling boot manoeuvre, the anklebeing stable at the test, a control X-ray hadshown a good joint congruence (Figure3). The ankle was immobilized in a plastered boot for 6 weeks without support followed by functionalrehabilitation. The functional result was excellent with a 6-month decline and sports recoverywasallowedat 3 months.

\section{Discussion:-}

Subtalar dislocation is a rare affection, very few cases have been described in medical books often in the form of isolated cases, the internalvarietyis the mostcommon and itis the factthat inversion is the main position of foot instabilitythatexplainsthishighfrequency [1,2]. The mechanism of medialsubtalar dislocation is a forced reversal with a foot blocked on the groundcausing a ligament rupture in a precisechronologicalorder: itis first the dorsal talonavicular ligament thatisinjured, then the two bundles of the interossal ligament or ligament in hedge and finally the calcaneo-fibularligament [3]. The clinicaldeformationisobvious and the diagnosisisconfirmed on analysis of standard $\mathrm{x}$-rays of the foot and ankleespecially the face incidence that shows the astragalus in place in the tibio-fibular mortaise while the foot ismovedinternally [3]. Treatment is emergency reductionundergeneralanesthesia. This is done by the maneuver of the boot, the kneebeingbending to relax the sural triceps. Irreducibilitymaybe the result of interpositions of the tendons of the fibulary muscles, the frond ligament, the short extensor muscle of the toes or a bone fragment for medial dislocations. The reductionisusually stable and does not justify, for pure dislocation, anyosteosynthesisprincipally [1] (plastered boot for 3 to 6 weekswithout support). The prognosis for these lesions is

\section{Corresponding Author: I. AIT Hadj Sliman}

Address:- Orthopaedic and Trauma Service at the Mohammed VI Marrakech University Hospital. 
relatively good for the most authorsexcept in cases of skin opening or associated fracture $[1,4,5]$. The risk of talian necrosis is estimated at $4 \%$ and that of subtalianosteoarthritisat $31 \%$ [5].

\section{Conclusion:-}

The internalsubtalarDislocation is a rare trauma affection, itsdiagnosisiseasy, the treatmentoftenconsists of a reduction by externalmaneuverundergeneralanesthesia, except in cases of irreducibility by incarcerationof a ligament where asurgicalreductionisrequired. These are a good prognosticlesionsexcept in cases wherethey are associatedwith a skin opening.

\section{Funding:}

None

\section{Conflicts of interest:}

The author's state thatthey have no conflicts of interest in relation to this article.

\section{Authors' contributions:}

All the authors contributed to the conduct of this work. All authors also state that they have read and approved the final version of the manuscript.

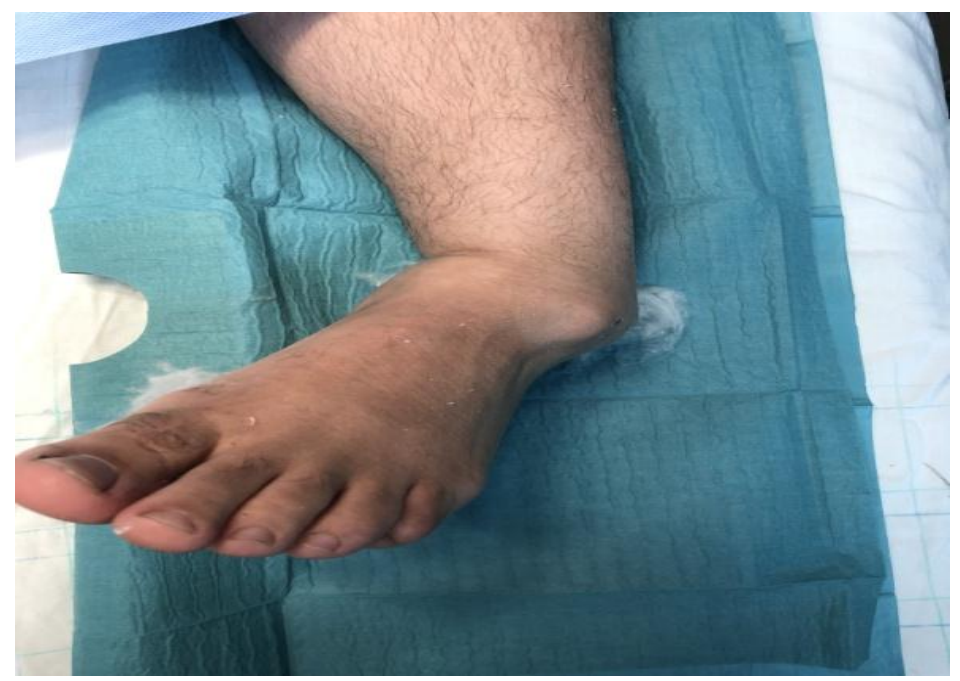

Figure 1:- Initial clinical inspection after trauma.

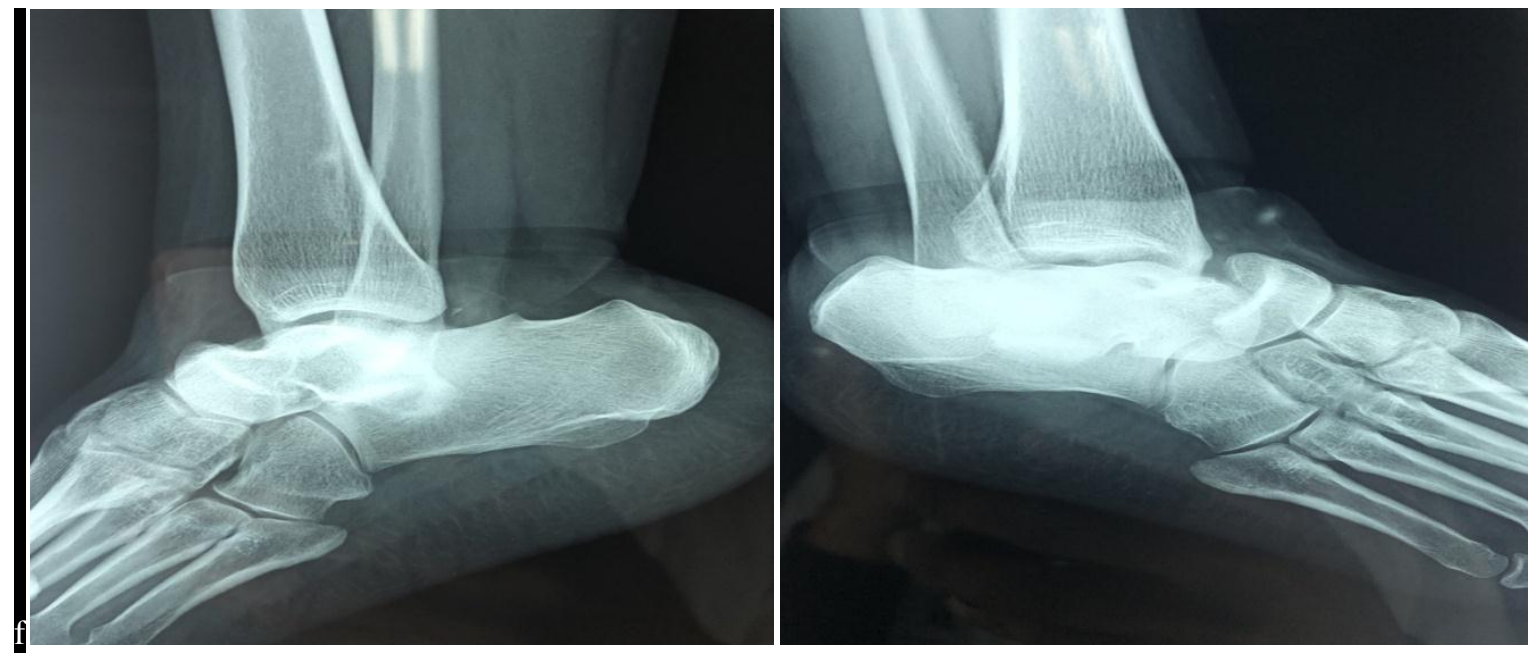

Figure 2:- Pre-reductional X-ray showingpureinternalsubtalar dislocation. 


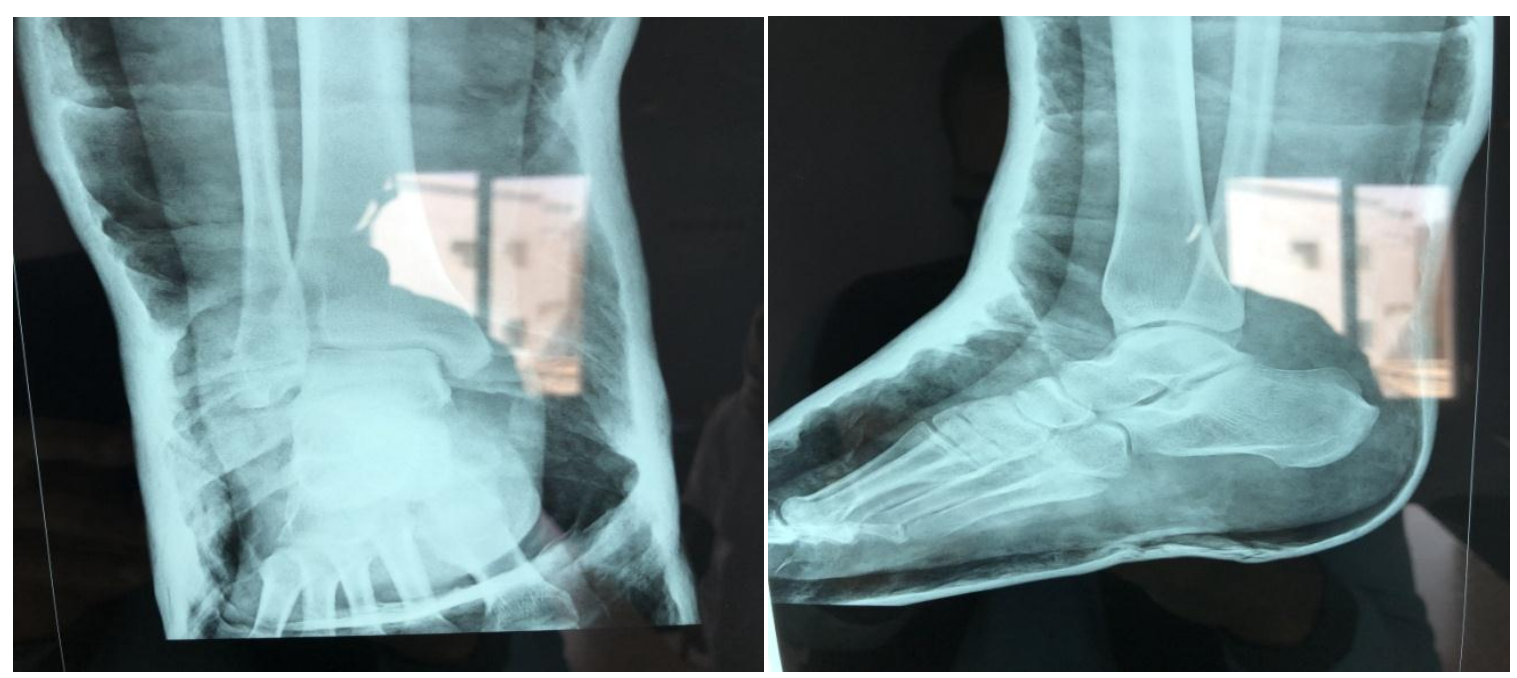

Figure 3:- X-rayAfterReductionShowing Good Joint Congruence.

\section{References:-}

1. Jarde O, Trinquier-Lautard JL, Mertl P, Tran F, Vives P. Les luxations sous-astragaliennes, à propos de 35 cas. RevChirOrthop. 1996; 82(1):42-8

2. JeromeJt, Varghese M, Sankaran B. Anteromedialsubtalar dislocation. J Foot AnkleSurg. 2007; 46(1):52-4

3. Amar MF, Chbani B, Loudiyi D et al.

Luxation sous-talienne pure chez un footballeur (à propos d'un cas). J Trauma Sport. 2009; 26(4) :250-252

4. Baumgartner A, Huguier A.

Les luxations sous-astragaliennes. RevChirOrthop suppl. 1983; 2 (69): 141-148

5. Schuind F, Andrianne Y, Burny F.

Fractures et luxations de l'astragale Revue de 359 cas. Acta OrthopBelg. 1983;49(6):652-689. 